\title{
La imagen del Camino de Santiago: Análisis de su representación promocional como producto turístico
}

\author{
Image of Camino de Santiago: Analysis of its promotional representation as a tourist product
}

\author{
María José Andrade Suárez
}

Universidade da Coruña, Rúa Maestranza, 9, 15001 A Coruña, Espanha, mandrade@udc.es

\section{Iria Caamaño Franco}

Universidade da Coruña, Rúa Maestranza, 9, 15001 A Coruña, Espanha, iria.caamano@udc.es

\section{Resumen}

En un contexto de intensa competitividad entre los destinos, la imagen turística se conforma como un importante elemento de diferenciación. Mientras que la imagen percibida se asocia con el conjunto de creencias e impresiones del turista sobre un destino; la imagen proyectada se afianza como un fenómeno de notable importancia de cara a la promoción y comercialización adecuada del éste. Se analizan en este trabajo las campañas de promoción realizadas por la Administración Autonómica sobre el Camino de Santiago en las últimas décadas- el contexto, la evolución, los actores, las estrategias de promoción, las acciones de comunicación, los materiales empleados y los símbolos de identidad- y la correspondencia entre la comunicación realizada (imagen proyectada) y la imagen percibida por los peregrinos -obtenida del análisis de 2.000 cuestionarios. El estudio empírico, que toma en consideración la imagen turística del Camino de Santiago desde el punto de vista de los turistas/peregrinos y la imagen que resulta de los folletos publicitarios, ha confirmado la existencia de ciertas diferencias entre ambas lo que permite identificar el nivel de ajuste y correspondencia entre estos elementos de cara a la mejora de la competitividad del destino.

Palabras clave: Imagen percibida y proyectada, promoción, marketing, Camino de Santiago.

\section{Abstract}

In the context of intense competition between destinations, the tourist image is an important element of differentiation. The perceived image is associated with beliefs and impressions about the destination; the projected image becomes an important phenomenon for the promotion and marketing of destinations. In this paper we analyze the promotion campaigns carried out by the regional administration about the Camino de Santiago in recent decades (the context, evolution, actors, promotion strategies, communication activities, materials and symbols) and the correspondence between communication (projected image) and the perceived image by the pilgrims (through the analysis of 2,000 surveys). The empirical study, which takes into account the tourist image of the Camino de Santiago from the point of view of tourists/pilgrims and the projected image, has confirmed the existence of some differences between both, which allows to identify the correspondence or fit between these elements to improve of destination competitiveness.

Keywords: Perceived image, projected image, promotion, marketing, Camino de Santiago.

\section{Introducción}

La importancia que adquiere la imagen en el desarrollo turístico de un lugar se pone de manifiesto en el elevado número de trabajos que, en las tres últimas décadas, se ha vertido en la literatura sobre este tópico desde diferentes enfoques. Hoy por hoy, es uno de los fenómenos más examinados dentro de la investigación en turismo (Gartner \& Shen, 1992; Chen \& Hsu, 2000; Tapachai \& Waryszak, 2000; Chen, 2001) y puede, asimismo, concebirse como uno de los temas que acumulan mayor atención y relevancia en la literatura (Fakeye \& Crompton, 1991; Walmsley \& Young, 1998; Beerli \& Martín, 2004).

El concepto de imagen resume la idea de que los consumidores o ciudadanos -peregrinos en nuestro caso- compran o eligen marcas no únicamente por sus características físicas o funcionales, sino también por el significado que tal producto tiene para la consecución de una serie de valores del individuo. Por esto, mantenemos que la "personalidad" del Camino de Santiago y de la marca Xacobeo no está solamente determinada por lo que ofrece (vivencia religiosa, espiritual, cultural, social, deportiva, gastronómica...) sino también por factores como la publicidad, aparición en informativos, opinión de los círculos culturales, etc. En definitiva, estas asociaciones evocadas por el recuerdo de la experiencia pueden ser percepciones específicas de atributos tangibles o funcionales pero también pueden ser asociaciones relacionadas con las emociones que el peregrino experimenta con dichos atributos.

La ruta del Camino de Santiago fue muy concurrida durante la Edad Media, después del siglo XIV fue ligeramente olvidada dadas las muchas convulsiones sociales que se produjeron en Europa y, en la época actual, ha vuelto a cobrar un gran auge. De hecho, el Camino de Santiago ha sido declarado por la Unesco Patrimonio de la Humanidad; Itinerario Cultural Europeo por el Consejo de Europa y ha recibido el título honorífico de Calle mayor de Europa.

Además, el número de peregrinos que llegan a Santiago de Compostela se incrementa sustancialmente cada año santo aunque fue a partir del Año Santo Compostelano de 1993 cuando el aumento fue realmente abrumador. En este año fue cuando el gobierno autónomo gallego decidió potenciar el valor del Camino enfocado a un recurso turístico; de este modo, se lanzó una gran campaña de publicidad: Xacobeo 93. Dentro de los preparativos de esta campaña destaca la creación -ya en el año 1991- de un Centro Coordinador Xacobeo (creado mediante el Decreto 377/1991 del 19 de septiembre), cuyo objetivo principal era unificar esfuerzos entre las distintas Administraciones e instituciones para potenciar el Camino.

La puesta en marcha del Plan Xaboceo' 93 tuvo como característica de diferenciación "el apoyarse en un evento de once siglos de historia que pretendía configurarse como una campaña en la que Galicia se constituyera como la meta del Camino, tratando de exhibir este protagonismo histórico y apoyarse en él como medio de dinamización económica y cultural de carácter permanente" (Fernández Souto, 2005). En definitiva, el Xacobeo'93 supuso la puesta en práctica de una campaña sin precedentes (actos lúdicos, culturales, grandes espectáculos...) para recibir a los ciudadanos de todo el mundo que desearon compartir la experiencia singular 
del Camino de Santiago, desde los más diversos lugares de partida hasta la meta compostelana.

Señalar también que el papel de los medios de comunicación de masas en toda esta campaña fue fundamental ya que tuvo lugar una presencia constante de Galicia en los medios de comunicación a todos los niveles -local, regional, nacional o incluso internacional- y el Gabinete de Comunicación del Plan Xacobeo atendió solicitudes de información procedentes de todos os continentes.

Así pues, la meta principal de este estudio es llevar a cabo un diagnóstico de la imagen del Camino de Santiago a través de un conjunto de atributos y asociaciones que el peregrino vincula con él.

Los objetivos específicos pasan por:

- Evaluar la imagen percibida del Camino de Santiago determinando las características únicas que en opinión de los peregrinos mejor lo definen y realizando al mismo tiempo un análisis de los principales componentes de la imagen: los cognitivos y los afectivos.

- Estudiar la imagen proyectada del Camino de Santiago mediante el análisis de las acciones realizadas para la promoción de la Ruta en las últimas décadas del siglo XX que lo llevaron a transformarse en un producto turístico bajo la marca Xacobeo.

A modo de conclusión se expondrá la correspondencia entre comunicación realizada (imagen proyectada) - realidad turística imagen conformada previa - imagen percibida a posteriori del Camino de Santiago.

\section{Revisión de la literatura}

En un contexto de intensa competitividad entre los destinos turísticos, la imagen percibida es un elemento clave y desempeña, a su vez, un papel fundamental en la elección del destino puesto que los valores que se asocian a ésta, representan un factor determinante en el proceso de decisión de compra de los potenciales turistas. De hecho, la imagen de un destino turístico incide considerablemente en su potencial de atracción ya que lo singulariza y distingue simbólicamente de otros (Antón \& González, 1997: 153).

De este modo, mientras que la imagen percibida se asocia con el conjunto de creencias e impresiones del turista sobre un determinado destino, la imagen proyectada se afianza como un fenómeno trascendental para la promoción y comercialización del mismo, cuyo éxito depende, por otra parte, del grado de congruencia entre la imagen proyectada y percibida del destino (San Martín, Rodríguez \& Vázquez, 2006). La distinción entre los conceptos imagen percibida y proyectada del destino (Gunn, 1972; Miossec, 1977; Bramwell \& Rawding, 1996; Galí \& Donaire, 2005) puede suponer una aproximación muy útil, no sólo a la hora de analizar conceptual y metodológicamente la imagen de destino, sino también para identificar las implicaciones que posibles desviaciones entre ambos conceptos pudieran presentar de cara a la promoción eficaz de los destinos turísticos.

De un lado, se encuentra la identidad (también denominada imagen emitida), definida como el conjunto de rasgos y atributos que definen la esencia de la cosa, algunos de ellos visibles y otros no (Villafañe, 2008a) y, por otro, la imagen (imagen percibida) que es la integración en la mente de sus públicos de todos los inputs emitidos sobre un ente determinado (Villafañe, 2008b). La situación descrita justifica la posición sumamente relevante que adquiere la imagen del destino turístico dentro de la investigación y la práctica de marketing. El estudio pormenorizado de la imagen de destino turístico responde, sin duda, a dos aspectos de especial trascendencia; en primer lugar, el interés de los académicos por explicar científicamente, la naturaleza y el proceso de formación de este concepto así como su influencia en el comportamiento de los turistas y, en segundo lugar, la necesidad que manifiestan los promotores de posicionar y diferenciar los destinos turísticos en la mente de sus públicos objetivo del modo más eficiente y eficaz posible.

La importancia que tiene la imagen en el desarrollo turístico de un lugar se pone de manifiesto en el elevado número de trabajos que, en las tres últimas décadas, se ha vertido en la literatura sobre este tópico desde diferentes enfoques. Hoy por hoy, es uno de los fenómenos más examinados dentro de la investigación en turismo (Gartner \& Shen, 1992; Chen \& Hsu, 2000; Tapachai \& Waryszak, 2000; Chen, 2001) y puede, asimismo, concebirse como uno de los temas que acumulan mayor atención y relevancia en la literatura (Fakeye \& Crompton, 1991; Walmsley \& Young, 1998; Beerli \& Martín, 2004).

Entre todas las definiciones de la imagen, puede destacarse por su amplitud y precisión la propuesta por Baloglu \& McCleary (1999), que consideran la imagen como la "representación mental de las creencias, los sentimientos y la impresión global del individuo sobre un destino turístico", lo que se denominará en la presente investigación, imagen percibida. Esta definición recoge las distintas dimensiones que, de acuerdo con la literatura, deben integrar el concepto imagen de destino. En concreto, incluye las evaluaciones tanto cognitivas, creencias o conocimientos que posee un individuo acerca de las características o atributos de un destino turístico, como las afectivas, representadas por los sentimientos hacia el destino.

De modo análogo, resulta relevante considerar que, dado que dicha imagen es definida por diversos autores como la percepción global o el conjunto total de impresiones sobre un lugar (Phelps, 1986; Fakeye \& Crompton, 1991) o como el retrato mental de un destino (Milman \& Pizam, 1995; Alhemoud \& Armstrong, 1996), es lógico pensar que ésta ejercerá alguna influencia sobre el comportamiento de los turistas (Cooper, Fletcher, Gilbert \& Wanhill, 1993) antes, durante y después de haber vivido la experiencia turística (Bigné, Sánchez \& Sánchez, 2001).

Así pues, del análisis de las definiciones presentadas, se deriva que la imagen de un destino es, en definitiva, todo lo que evoca el destino en el individuo (ideas, creencias, sentimientos o actitudes que asocia con el lugar), y que ésta no se limita a la percepción de estímulos sensoriales, sino que incluye también códigos semánticos, y se ve afectada tanto por factores internos como externos al individuo (Sanz, 2008: 99).

Además, a la afirmación de que el mundo es una percepción o representación psicológica de la realidad que reside en la mente 
del individuo (Baloglu \& McCleary, 1999), habría que añadirle que ésta, además, es producida en contextos sociales e históricamente conformados (Morgan \& Pritchard, 1998).

En este sentido, la imagen turística proyectada, considerada en la literatura como un factor "de atracción" en el proceso de elección de un destino turístico (Andreu, Bigné \& Cooper, 2000), es aquella que se traslada hacia su mercado de referencia a través de los distintos canales de comunicación. Dentro de éstos, conviene destacar la presencia de las oficinas de turismo, las agencias de viajes o los tour operadores (Middleton, 1994; Pritchard, 1998), que se muestran estrechamente relacionados con la propia realidad del destino, así como también el papel desempeñado por los organismos turísticos públicos, tanto dentro de los agentes inducidos como por su repercusión sobre los agentes orgánicos. En su función como responsable de marketing de los destinos, éstos emplean una gran cantidad de dinero, tiempo y esfuerzos para crear imágenes favorables que ayuden a atraer a turistas potenciales al lugar (Baloglu \& McCleary, 1999), ya que los destinos, a menudo, compiten únicamente mediante las imágenes que los turistas potenciales poseen sobre los mismos.

Al mismo tiempo, los comercializadores del destino tratan de diversificar sus productos ofreciendo distintas imágenes en función de los segmentos a los que se dirijan. En consecuencia, los organismos encargados de promocionar destinos turísticos no sólo deben esforzarse por proyectar imágenes adecuadas a sus planteamientos, sino que también es necesario llevar a cabo investigaciones sobre el comportamiento de consumidor, centradas en el análisis de los factores que influyen en éste para la elección del destino de vacaciones (Andreu, Bigné \& Cooper, 2000).

El sujeto de la mirada, el turista-actor, aprehende la imagen como parte de sus procesos cotidianos y como un objeto de la cultura que visita (normalmente oculta tras el velo de la actividad turística) en un ejercicio de codificación, interpretación y valoración comparativa desde su modo de vida y cultura de origen, mediado por el sistema turístico y yuxtapuesto a los estereotipos y expectativas acumuladas antes de la visita (Santana, 2007). Los espacios turísticos acaban siendo valorados como tales en función de la percepción que los visitantes tienen de ellos y, a su vez, este proceso de valoración parte de la propia experiencia de los turistas, pero también del proceso de producción de imágenes asociadas a los destinos en cuestión (Antón \& Gónzalez, 2007: 153).

En un ámbito más concreto, según afirma Santana Talavera (2007: 9), su objetivo es contribuir a consolidar la decisión de compra sobre un destino y un tipo de turismo determinado. En este punto, es atribuible a la imagen promocionada, tanto el papel de generadora y reforzadora de estereotipos sobre el destino (Echtner \& Ritchie, 1991; Gallarza, et al; 2002), como de promotora de expectativas (Litvin \& MacLaurin, 2001) sobre el área, los productos promocionados y las emociones causadas por su consumo.

\section{Metodología}

La sistematización de una recogida de información de naturaleza cuantitativa, seguida del pertinente análisis estadístico, constituye un primer paso para la comprensión y delimitación de la imagen del Camino de Santiago. El acopio de datos fue efectuado mediante una serie de encuestas personales realizadas en el casco histórico de Santiago de Compostela a una muestra representativa de peregrinos una vez habían llegado a la ciudad en 2010. El marco muestral de referencia utilizado han sido los datos de la Oficina Virtual del Peregrino (http://peregrinossantiago.es/esp/). A continuación, se muestra la ficha técnica de la investigación (Figura 1).

Figura 1 - Ficha técnica del estudio

\begin{tabular}{|c|c|}
\hline Características & Encuesta \\
\hline Universo & $\begin{array}{l}\text { Peregrinos que llegaron a Santiago en el año } \\
2010\end{array}$ \\
\hline Ámbito geográfico & Santiago de Compostela \\
\hline Forma de contacto & $\begin{array}{l}\text { Encuesta personal o autocumplimentada en } \\
\text { los alrededores de la Catedral de Santiago, } \\
\text { en función de un marco muestral no } \\
\text { probabilístico por cuotas (sexo, grupo de } \\
\text { edad, ruta de peregrinación elegida y país de } \\
\text { residencia) }\end{array}$ \\
\hline Muestra definida & 2.000 encuestas \\
\hline Muestra real & 2.131 encuestas válidas \\
\hline Error muestral & $2,1 \%$ \\
\hline Nivel de confianza & $95 \%$ \\
\hline $\begin{array}{l}\text { Fecha trabajo de } \\
\text { campo }\end{array}$ & Julio-Noviembre 2010 \\
\hline
\end{tabular}

Fuente: Elaboración propia.

Así pues, para evaluar la imagen percibida del destino turístico, se emplearon varias escalas diferentes:

1. Debe destacarse que un número importante de trabajos asume que la imagen es un constructo multidimensional, abordando la medición del componente común de la misma a través de la metodología estructurada la cual está fundamentada en la aplicación de una batería de atributos o características relevantes del destino fijadas de antemano por los propios investigadores. Los atributos son obtenidos mediante la realización de estudios exploratorios en base a la revisión bibliográfica $y$, posteriormente, se completan mediante los resultados obtenidos en diversas entrevistas en profundidad y/o grupos de discusión.

a. Así, con la finalidad de medir el componente cognitivo de la imagen, se eligieron 10 atributos cognitivos con diferente posición en el continuo funcional-psicológico (Echtner \& Ritchie, 1991; Gallarza, Gil \& Calderón, 2002). La opinión de que dispone inicialmente el turista de los atributos cognitivos es recogida mediante una escala Likert de 5 posiciones $(1=$ total desacuerdo; $5=$ total acuerdo).

b. La evaluación de los atributos que forman parte del componente afectivo se llevó a cabo empleando una escala bipolar de diferencial semántico de 4 ítems y 7 puntos: aburrido-divertido, estresante-relajante, deprimente-excitante, desagradable-agradable, 
siguiendo la propuesta de los trabajos empíricos de autores como Russel \& Pratt (1980) y utilizados en diversos estudios.

2. La valoración de la imagen global se mide a través de un único ítem preguntando a los encuestados: "En general, ¿qué imagen tiene usted del Camino de Santiago?" Para codificar las respuestas, se utilizó una escala Likert de 7 puntos que oscila desde muy negativa (1) hasta muy positiva (7)

3. El componente único de la imagen se mide a través de la siguiente cuestión: "Indique aquellas atracciones y características que, a su juicio, son únicas o distintivas del Camino de Santiago". Esta propuesta tiene por objeto solicitar a los sujetos que señalen las atracciones que consideran únicas y distintivas de ese destino.

Respecto a la imagen proyectada, se les planteaba a los peregrinos que indicaran si estaban de acuerdo con alguna de las siguientes afirmaciones:

- La realidad del Camino es todavía mejor a lo que se dice

- Lo que se dice se corresponde con la realidad vivida durante el peregrinaje

- Lo que se dice supera a la realidad (el Camino está sobredimensionado).

Para dar respuesta a los objetivos propuestos se plantea asimismo una fase cualitativa en la que se realiza un análisis de contenido para estudiar la aparición del producto Camino de Santiago en las campañas de promoción turística de carácter institucional realizados desde la administración, anteriormente Turgalicia S.A. y, en la actualidad, Axencia de Turismo de Galicia.

Se han analizado las campañas más significativas desde el 2006 por considerarse un punto de inflexión en la gestión publicitaria apostando desde aquel entonces por trasladar el destino a través de la sensibilidad si bien es cierto que Galicia se posiciona a nivel mundial a partir del 2002 coincidiendo con la tragedia del Prestige.

A través del análisis de contenido se identifican los significados de cada anuncio, cartel o folleto según el tipo de consumidor destinatario del mensaje y se ha analizado asimismo la marca Camino de Santiago que recoge el discurso común presente en las diferentes campañas. Por otra parte, se examinan también las actuaciones realizadas para la difusión del Xacobeo en sus ediciones de 1993, 1999, 2004 y 2010.

\section{Resultados}

\subsection{Análisis de la imagen turística percibida del Camino de Santiago}

Como podemos en el análisis de la imagen percibida a nivel cognitivo (Figura 2), la belleza del paisaje es el atributo que obtiene una mayor puntuación de todo el listado (alcanzando el 4,56 sobre 5) seguido de la adecuada señalización y los atractivos monumentales. Por otro lado, aunque conviene destacar lo elevado de las puntuaciones de todos los ítems, al final del listado se sitúan los atributos relacionados con la calidad de la hostelería (hospedajes, comidas y relación calidad precio).
Figura 2. Análisis descriptivo de los atributos cognitivos de la imagen del Camino de Santiago

\begin{tabular}{|l|c|c|}
\hline \multirow{2}{*}{\multicolumn{1}{|c|}{ Listado de atributos }} & \multicolumn{2}{c|}{ Importancia } \\
\cline { 2 - 3 } & Media & D. T. \\
\hline Belleza del paisaje & 4,56 & 0,70 \\
\hline Señalización adecuada & 3,97 & 1,02 \\
\hline Atractivos monumentales & 3,91 & 0,94 \\
\hline Conservación de la ruta & 3,83 & 0,98 \\
\hline Amabilidad lugareños & 3,75 & 1,11 \\
\hline Limpieza y cuidado del entorno & 3,71 & 1,01 \\
\hline Servicio de información al peregrino & 3,51 & 1,05 \\
\hline Servicio de restaurantes y comida & 3,33 & 1,04 \\
\hline Calidad alojamientos & 3,31 & 0,98 \\
\hline Relación calidad-precio & 3,26 & 1,11 \\
\hline \multicolumn{1}{|c|}{ Fuente: Elaboración propia. } & \\
\hline
\end{tabular}

Del análisis de la imagen percibida del Camino de Santiago a nivel afectivo (Figura 3), indicar que la opinión global que tienen los peregrinos acerca de su experiencia fue medida en una escala Likert de 7 posiciones, desde el 1 (totalmente aburrido, estresante, deprimente o desagradable) hasta 7 (totalmente divertida, relajante, excitante o agradable); y los resultados muestran, en general, una percepción de la experiencia como bastante favorable. Destaca, sobre todo, la calificación de la experiencia como divertida y agradable (con un 5,91 y un 5,76 respectivamente) aunque la categoría con menor puntuación es la percepción del Camino como una experiencia relajante.

Figura 3 - Análisis descriptivo de los atributos afectivos de la imagen del Camino de Santiago

\begin{tabular}{|l|c|c|}
\hline \multicolumn{1}{|c|}{ Listado de atributos } & Media & D. T. \\
\hline Experiencia aburrida-divertida & 5,91 & 1,134 \\
\hline Experiencia estresante-relajante & 4,69 & 1,601 \\
\hline Experiencia deprimente-excitante & 5,29 & 1,614 \\
\hline $\begin{array}{l}\text { Experiencia desagradable- } \\
\text { agradable }\end{array}$ & 5,76 & 1,643 \\
\hline
\end{tabular}

Fuente: Elaboración propia.

Por otra parte, en relación a los resultados sobre la imagen global que los peregrinos tienen del Camino de Santiago, donde las respuestas podían oscilar dentro de una Likert de 7 puntos y se les señalaba que varían entre el 1 (muy negativa) hasta el 7 (muy positiva), es preciso indicar que la puntuación media que los peregrinos tienen del Camino de Santiago es muy elevada -6 puntos sobre 7 (con desviación típica es de 1,061)- lo que supone un adecuado posicionamiento del mismo en la mente de los peregrinos.

En la Figura 4 se presenta una tabla de frecuencias con las características más distintivas del Camino de Santiago donde se recogen los conceptos mencionados por los peregrinos (que representan un porcentaje igual o superior al 3\% de los casos) relativos al componente único de la imagen del Camino de Santiago como destino turístico el cual se mide a través de la 
siguiente pregunta abierta: "Indique aquellas atracciones y características que, a su juicio, son UNICAS O DISTINTIVAS del peregrinaje a Santiago de Compostela" (otorgando la posibilidad de indicar hasta tres respuestas). Para el análisis de las preguntas abiertas se confeccionó, en primer lugar, una tabla de codificación y se procedió a eliminar contenidos ambiguos cuya información no resultaba relevante. A continuación, después de haber grabado todas las respuestas válidas a las preguntas abiertas en un documento de Excel, se llevó a cabo un detallado trabajo de clasificación de las respuestas en categorías.

Figura 4 - Análisis descriptivo del componente único de la imagen del Camino de Santiago

\begin{tabular}{|c|c|c|}
\hline Componente único & N & Porcentaje \\
\hline \multicolumn{3}{|c|}{ Respuestas dadas en primer lugar } \\
\hline La gente que conoces & 222 & 37,44 \\
\hline Arte y cultura & 40 & 6,75 \\
\hline Paisaje - naturaleza & 24 & 4,05 \\
\hline \multicolumn{3}{|c|}{ Respuestas dadas en segundo lugar } \\
\hline La gente que conoces & 308 & 26,37 \\
\hline Paisaje - naturaleza & 216 & 18,49 \\
\hline Arte y cultura & 47 & 4,02 \\
\hline \multicolumn{3}{|c|}{ Respuestas dadas en tercer lugar } \\
\hline La gente que conoces & 102 & 6,26 \\
\hline Paisaje - naturaleza & 74 & 4,54 \\
\hline
\end{tabular}

Como se puede apreciar, en todos los órdenes de respuestas, los conceptos más nombrados son los relativos a la gente que se va conociendo durante el peregrinaje (principalmente otros peregrinos, aunque también aparecen mencionados residentes $y$ hospitaleros) y la unión creada entre ellos, es decir, compañerismo, ayuda, lealtad... Esta categoría supone prácticamente un $37,5 \%$ de las respuestas en primer término. Resaltar también que las respuestas relativas al paisaje están en torno al $4 \%$ en cualquiera de los distintos órdenes de respuesta y que en esta categoría se agrupan todas las respuestas relativas a la belleza del paisaje, al contacto diario con la naturaleza y el medio rural, etc. También puntúan (aunque con muy distinto peso como podemos comprobar en la tabla) el patrimonio históricocultural del Camino de Santiago: mientras que en las respuestas dadas en primer término representa un $6,75 \%$ en las respuestas dadas en segundo término alcanza el $18,5 \%$

\subsection{Análisis de la imagen proyectada del Camino de Santiago}

El Año Santo Compostelano de 1993 fue el primero en ser promocionado de modo intenso por parte de las instituciones autonómicas conscientes de la importante trascendencia, incidencia y potencialidad que el evento representaba para la revitalización y dinamización de Galicia (Álvarez Sousa; Gomis Rodríguez y Gallego Valiña, 2010).

Uno de los grandes objetivos del Plan Xacobeo 93 fue la promoción exterior de Galicia con el objetivo de comunicar una nueva imagen de país "en pleno desarrollo, que mira al siglo XXI, pero que cuenta con un impresionante patrimonio cultural y artístico" (Xunta de Galicia, 1994:100), tratando así de romper con la antigua imagen y los estereotipos de territorio aislado y atrasado respecto del resto de España.

A partir de esta premisa, la sociedad creada para la gestión y promoción del Xacobeo ha desempeñado en cada año jubilar una intensa labor de comunicación con la finalidad de dar a conocer la extensa gama de eventos y actividades que tienen lugar con motivo del año santo. En general, las tareas de promoción del Xacobeo se centran en la asistencia a ferias, el patrocinio de actividades deportivas, la presencia en actos culturales e institucionales, la elaboración de folletos y guías, etc.

Al igual que cualquier otro gran evento que desee promocionarse adecuadamente, comunicando una imagen de marca, el Xacobeo necesitaba disponer de una imagen característica que lo identificase y expresase los valores del acontecimiento. Así, con motivo del año santo del año 1993, el diseñador gallego Luís Carballo elaboró un logotipo y una mascota para actuar de símbolos del evento bajo el nombre de Pelegrín, el cual evoca la tradicional figura del peregrino medieval desde una perspectiva vanguardista y moderna a partir del tradicional bastón. El logotipo se completa con las palabras Xacobeo y Galicia (Imagen 1). La mascota continúa siendo un símbolo de identidad del Xacobeo aunque se cambiaría con motivo del Xacobeo de 1999 aunque continuó en el 2004 y posteriormente se decidió cambiarlo para el año 2010 ya que ya no alcanzaba el reclamo originario (Álvarez Sousa; Gomis Rodríguez y Gallego Valiña, 2010: 31-33).

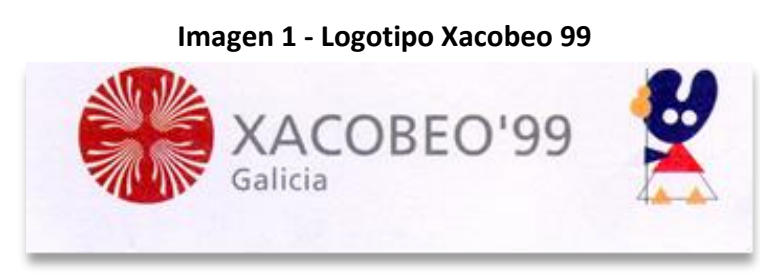

En el año 1999, el diseño de una nueva imagen corporativa que resultase innovadora fue una de las principales prioridades para la promoción y difusión del Xacobeo (Xunta de Galicia, 2000: 45), lo que dio como resultado la creación de un nuevo y moderno logotipo elaborado por Alberte Permuy inspirándose en la tradicional concha del peregrino, uno de los atributos más identificativos del Camino de Santiago. Esta asociación de la concha con la Ruta Jacobea se remonta al inicio de la historia de las peregrinaciones y del culto a Santiago, y su imagen puede verse aún hoy en día en numerosos edificios de Santiago así como del resto de Europa (Xunta de Galicia, 2000: 47).

La imagen para el Xacobeo 99 está formada por una moderna y estilizada concha de peregrino de color blanco repetida cuatro veces, enmarcadas dentro de un círculo de color rojo. El logotipo se completa con la denominación del evento y Galicia. La disposición en forma de aspa de las cuatro conchas se asemeja a unos brazos abiertos, transmitiendo una sensación de acogida y hospitalidad, cualidades que Galicia siempre posee con todo aquel que se acerca a visitarla, ya sea como peregrino o como un turista más. Del mismo modo, esta disposición dirige la mirada directamente hacia el centro del círculo, sugiriendo la idea de Santiago de Compostela como punto de encuentro de los diferentes caminos de peregrinación (Álvarez Sousa; Gomis 
Rodríguez y Gallego Valiña, 2010: 33-34). En definitiva, la sencillez y versatilidad del logotipo del Xacobeo 99 desempeñó en todo momento su papel de marca y su inmediata identificación con Galicia y el Xacobeo lo que impulsó, al igual que sucediera en 1993 con el Pelegrín, la decisión de adoptarlo como símbolo permanente del Xacobeo para el 2004.

Sin embargo, la imagen del Xacobeo simbolizada fundamentalmente por la mascota del Pelegrín, después de un período de alza en el 1993 fue decayendo poco a poco. Así, el logotipo de 2004 (Imagen 2) consiste en una reinterpretación de la flecha amarilla, universalmente vinculada al Camino de Santiago desde que un párroco de $O$ Cebreiro (Lugo), a falta de ayudas oficiales, recorrió el Camino Francés con su coche cargado de botes de pintura amarilla y así fue pintando flechas amarillas para orientar a los peregrinos.

Imagen 2 - Logotipo Xacobeo 2004
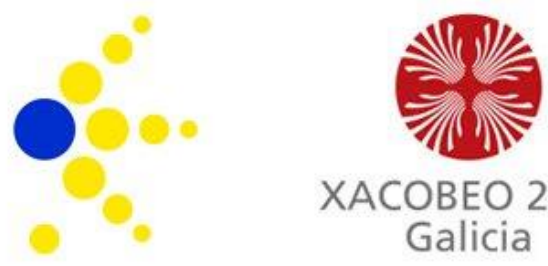

XACOBEO 2004 Galicia

No obstante, con la entrada de un nuevo gobierno, para el Xacobeo de 2010 se abandona este logo y se retoma el anterior basado en la concha, pues se cree que ya es muy conocido a nivel mundial y eso favorecerá la promoción (Álvarez Sousa; Gomis Rodríguez y Gallego Valiña, 2010: 35). Ver imagen 3.

Imagen 3 - Logotipo Xacobeo 2010

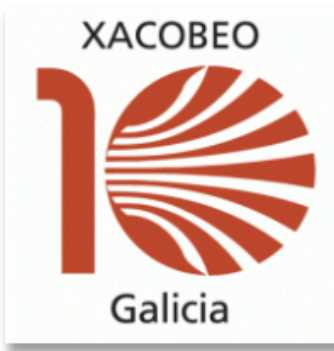

En relación a las campañas de promoción turística a nivel institucional, indicar que en el año 2006, Turgalicia promueve una campaña para la promoción del destino con el slogan "Galicia, sí, es única" apelando así a los sentimientos a través de la naturaleza gallega (carballeira, morriña, lusco fusco...) con la finalidad de captar turismo nacional. La imagen proyectada difunde así una visión "mágica", mística y de tranquilidad. El papel del Camino de Santiago en esta campaña es nulo a pesar de que aparece una imagen de un grupo de amigos caminando entre un bosque que, aunque representa la naturaleza y la posibilidad de realizar senderismo, no es el propio Camino de Santiago.

A partir de ese año se crea el Plan Estratégico 2007-2010 de Turgalicia por el que se rigen las campañas de comunicación posteriores. El objetivo será promocionar un destino atlántico, con un estilo de vida diferente, con relaciones humanas cálidas y amables, ritmo de vida sosegado, dieta atlántica y recursos únicos así como el apego a la tierra y a la naturaleza haciendo hincapié en la relación especial de los gallegos con el agua: el océano, la lluvia, las aguas termales y las aguas interiores. Y no olvida el Camino de Santiago y los centros históricos de las ciudades (Turgalicia, 2007).

De manera similiar a la campaña anterior, utilizando la voz en off del famoso actor Luis Tosar así como la música de Luar na Lubre se lanza en 2007 una nueva campaña de "Galicia, Destino Atlántico" y "Galicia segue sendo única". En el año 2008, la promoción continuará bajo el slogan "Destino Atlántico" que busca transmitir el estilo de vida en Galicia. Se intentó también reforzar el Turismo Profesional, el Turismo de Golf, el Turismo Idiomático y el Turismo Familiar.

La campaña del 2009, "Galicia ven, siéntela", hace mayor hincapié en los sentimientos $y$, aunque sigue una línea similar a las anteriores campañas (tranquilidad, mar, playa...), el papel del Camino de Santiago ya se aprecia directamente con las imágenes de peregrinos caminando y llegando a Compostela. A finales de año ya se presenta el plan de actuaciones para el Xacobeo 2010. La intención no era sólo promocionar el Año Santo, sino sentar las bases para que la marca Galicia fuese más reconocida y valorada en los mercados turísticos nacionales e internacionales (Turgalicia, 2010). De este modo, en 2010, al ser Año Santo, la S.A. De Xestión do Plan Xacobeo puso en marcha varias campañas publicitarias en televisión y medios on-line españoles bajo el slogan "Ahora es cuándo, Galicia es dónde" el cual acopia en seis palabras que Galicia se trata de un destino que es preciso visitar y que, durante ese año, es el momento ya que todo y todos pasan por Galicia. Se incluyeron así referencias al Camino de Santiago tratando de buscar el lado más humano a través de las personas, sus historias y sus motivos para hacer el Camino. En definitiva, dos fueron los ejes principales de la comunicación: animar a los turistas a venir a Galicia a celebrar el Año Santo y a los gallegos a festejarlo (Turgalicia, 2010).

A principios del año 2011 se lanzó "Galicia, pensando en volver a ti", que será visto en canales televisivos de todo el país y se centra en la divulgación de las principales potencialidades turísticas que posee la comunidad a través del encuentro de una pareja de jóvenes que disfruta de la naturaleza, la gastronomía, el turismo rural y de aventura, el termalismo, etc. Pero, a mediados del año, se lanza lo que será una de las campañas mejor valoradas para la promoción de la comunidad: “¿Me guardas el secreto?”. Aquí se trata de mostrar la amabilidad de las gentes en Galicia así como la parte misteriosa sin olvidar el mar y el agua. El lanzamiento de esta campaña coincidió justo con la finalización del año Xacobeo y trataron de aprovechar el tirón que éste supuso, puesto que fue uno de los mejores años en cuanto a cifras de número de turistas se refiere. No obstante, sigue sin aparecer el Camino de Santiago en las campañas de promoción a pesar de ser el producto estrella

Siguiendo con el ejemplo del 2010 de intentar implicar a los gallegos en la mejora de la imagen de Galicia ante los turistas, con la campaña de 2014 "Presume de Galicia” se lanzó el eslogan de "a la gente que quiero le recomiendo Galicia". A pesar de que el slogan hace de referencia de manera indirecta al Camino de Santiago si que es cierto que en el vídeo promocional no aparece reflejado en ningún momento.

\section{Discusión y Conclusiones}

El estudio pormenorizado de la imagen del destino turístico responde, sin duda, a dos aspectos de especial trascendencia; en 
primer lugar, el interés de los académicos por explicar científicamente la naturaleza y el proceso de formación de este concepto así como su influencia en el comportamiento de los turistas $y$, en segundo lugar, la necesidad que manifiestan los promotores de posicionar y diferenciar los destinos turísticos en la mente de sus públicos objetivo del modo más eficiente y eficaz posible (Andrade Suárez \& Caamaño Franco, 2013).

La imagen que los destinos turísticos proyectan sobre sus potenciales turistas es un tema de interés central para los organismos encargados de promocionar destinos turísticos pero, junto a este concepto de imagen emitida, se hace también fundamental la identificación de la imagen percibida por el turista para determinar la competitividad del destino. Así, en nuestro caso, el "potencial peregrino" se enfrenta a destinos alternativos para sus vacaciones y su proceso de elección dependerá de varios factores, entre los que destaca la imagen que percibida del mismo. Los resultados obtenidos en este trabajo de investigación reúnen gran interés puesto que permiten identificar cuáles son las fortalezas y las debilidades del Camino de Santiago en la mente de los peregrinos y promoverlo de manera eficaz como destino turístico.

En relación a la imagen percibida del Camino de Santiago, en el presente estudio se realiza una investigación in situ puesto que el peregrino todavía no ha regresado a su lugar de residencia habitual. Así, del análisis de la imagen percibida a nivel cognitivo se desprende que la belleza del paisaje es el atributo mejor valorado junto con la adecuada señalización y los atractivos monumentales; al final del listado se sitúan los atributos relacionados con la calidad de la hostelería (hospedajes, comidas y relación calidad precio). De nuestro análisis de la imagen percibida del Camino de Santiago a nivel afectivo destaca la calificación de la experiencia como divertida y agradable.

En cuanto a la imagen general del Camino de Santiago: el abrumador porcentaje del $91,1 \%$ de la muestra se posiciona en el lado positivo de la escala, aumentando el porcentaje a medida que aumenta la posición en la misma. Resaltamos además que una proporción importante de los peregrinos incluidos en la muestra un $39,2 \%$ - perciben la imagen general del Camino de Santiago como totalmente positiva.

Por otro lado, la técnica no estructurada nos ha permitido conocer las características únicas respecto a la imagen del Camino de Santiago; y, aunque lo más destacado es la unión creada durante el peregrinaje entre personas desconocidas y dispares en cuanto a características socio demográficas pero igualadas por la meta común de llegar a Santiago, el "paisaje y el contacto con la naturaleza" y el "arte y la cultura" son las únicas dos categorías que puntúan significativamente después de la mayoritaria ya comentada.

Así pues, la imagen percibida del destino pone en evidencia que, aunque la mayor parte de los recursos turísticos son de carácter objetivo y tangible; sin embargo, la percepción de los mismos puede ser diversa debido a la naturaleza subjetiva de ésta (Bigné et al., 2001; Leisen, 2001; Gallarza et al., 2002). En definitiva, es necesario comprender las imágenes que poseen los turistas, así como el papel de factores internos y externos que influyen en su formación, con el fin de mejorar el posicionamiento de los destinos turísticos en los mercados objetivo.

Si acabamos de analizar las imágenes turísticas percibidas, pasamos ahora a analizar las imágenes turísticas proyectadas. En síntesis, desde el punto de inflexión que se considera el año 2006, las campañas y los carteles hasta la actualidad son semejantes entre sí siguiendo la misma línea estratégica de actuación durante este período así como la intencionalidad de los sloganes y las imágenes de los vídeos promocionales en los que prácticamente no se hace referencia al Camino de Santiago sino que se intentan enfatizar los significados de cultura, naturaleza, gastronomía y tranquilidad.

Como se puede observar en la Figura 5, para la mayor parte de la muestra del estudio, la experiencia y realidad vivida se equipara a la imagen proyectada del Camino de Santiago $(44,8 \%)$ aunque el porcentaje de peregrinos para los que la realidad vivida supera a la imagen que se proyecta del Camino de Santiago es de un $42,5 \%$. Destaca el hecho de que solamente el $12,75 \%$ de los peregrinos encuestados sostenga que el Camino del Santiago esté sobredimensionado.

Figura 5 - Análisis de las opiniones de los peregrinos sobre la imagen proyectada del Camino de Santiago

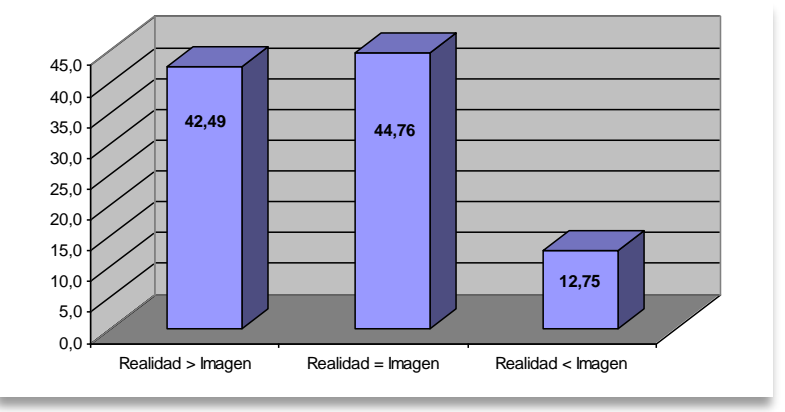

Fuente: Elaboración propia

Los resultados muestran que, en general, los turistas que visitan Santiago de Compostela no lo hacen debido a una publicidad impulsiva, sino porque después de informarse deciden hacer el camino para tener una vivencia que esperan encontrar de forma relajada. Coinciden en que la imagen que se proyecta del Camino es precisamente la de proporcionar esa información y si fuese de otro tipo más impulsiva -como en otros lugares turísticos-, perdería la identidad. Creen en general que la imagen proyectada se queda escasa comparada con la realidad del Camino, no sólo por los objetos materiales que se encuentran, sino sobre todo por las vivencias que se tienen en el Camino y que son imposibles en cualquier otro lugar de turismo (Álvarez Sousa; Gomis Rodríguez y Gallego Valiña, 2010: 37).

Dado que la imagen se va formando como resultado acumulativo de todos los mensajes que se reciben referidos al objeto (en nuestro caso, el Camino de Santiago), se deduce que esta imagen existirá de todos modos, tanto que sea deseada como no por los "gestores" del objeto. En la actualidad, no siempre los "gestores" son conscientes de esto, renunciando a cierto control de su imagen, lo que significa aceptar implícita o explícitamente una imagen espontánea -no controlada- a partir del público con ese objeto. Es preciso destacar que los destinos turísticos compiten 
fundamentalmente sobre la base de su imagen percibida en relación con los destinos competidores (Baloglu \& Mangaloglu, 2001), y, en consecuencia, alcanzar una posición competitiva sólida requiere el desarrollo de una imagen positiva en los mercados objetivo (Gartner, 1993; Baloglu \& McCleary, 1999b).

Teniendo en cuenta estas premisas, la gestión estratégica de la imagen resulta más adecuada y eficiente una vez que se conocen los atributos que la configuran y la importancia que cada uno de ellos tiene para el turista lo que permite, entre otros aspectos, identificar las fortalezas y debilidades que presenta el destino turístico (Bramwell \& Rawding, 1996; Baloglu \& Mangaloglu, 2001; Chen \& Uysal, 2002), promocionar de modo eficiente y eficaz el destino hacia su mercado de referencia (Calantone et al; 1989; Chon, 1990; Leisen, 2001; Cannon Hunter, 2012), facilitar el desarrollo turístico de una área geográfica (Choi, Chan \& Wu, 1999) o garantizar el éxito competitivo de un determinado destino (Telisman-Kosuta, 1994; Font, 1997).

En definitiva, la imagen se convierte en un aspecto básico en el análisis del comportamiento del turista antes, durante y después de haber vivido la experiencia turística (Bigné, Sánchez \& Sánchez, 2001), línea de investigación o hipótesis que correspondería verificar a partir de la información obtenida en este trabajo acerca de la naturaleza de la imagen percibida del Camino de Santiago.

\section{Referencias}

Álvarez Sousa, A., Gomis Rodríguez, A. \& Gallego Valiña, M. A. (2010). Estructura organizativa e imagen promocional del Camino de Santiago. Rotur: Revista de Ocio y Turismo, 3, 11-38.

Andrade Suárez, M. J. \& Caamaño Franco, I. (2013). Attributes and social imaginary produced by tourists about rural areas. Rotur: Revista de Ocio y Turismo, 6, 1-12.

Antón Clavé, S. \& González Reverté, F. (1997). Opciones del turismo para el desarrollo sostenible de los espacios rurales. En Valenzuela Rubio, M. (Coord.), Los turismos de interior: el retorno a la tradición viajera (pp. 6169). Madrid: Universidad Autónoma de Madrid.

Antón Clavé, S. \& González Reverté, F. (Coord.) (2007). A propósito del turismo: la construcción social del espacio turístico Barcelona: UOC.

Alhemoud, A. M. \& Armstrong, E. G. (1996). Image of tourist attractions in Kuwait. Journal of Travel Research, 34(4), 76-80.

Andreu, L., Bigné, J. E. \& Cooper, C. (2000). Projected and perceived image of Spain as a tourist destination for British travellers. Journal of Travel \& Tourism Marketing, 9(4), 47-67.

Baloglu, S. \& Brinberg, D. (1997). Affective Images of Tourism Destinations. Journal of Travel Research, 35(4), 11-15.

Baloglu, S. \& Mangaloglu, M. (2001). Tourism destinations images of Turkey, Egypt, Greece, and Italy as perceived by US-based tour operators and travel agents. Tourism Management, 22, 1-9.

Baloglu, S. \& McCleary, K. W. (1999). A model of destination image formation. Annals of Tourism Research, 26(4), 868-897.

Beerli Palacio, A. \& Martín Santana, J. (2004). Tourists' Characteristic and the Perceived Image of Tourist Destinations: A Quantitative Analysis - A Case Study of Lanzarote, Spain. Tourism Management, 25(5), 623-636.

Bigné, J. E. \& Sánchez, M. I. (2001). Evaluación de la imagen de destinos turísticos: una aplicación metodológica en la Comunidad Valenciana. Revista Europea de Dirección y Economía de la Empresa, 10(3), 189-200.

Bramwell, B. \& Rawding, L. (1996). Tourism marketing images of industrial cities. Annals of Tourism Research, 23(1), 201-221.

Calantone, R. J., Di Benedetto, C. A., Hakam, A. \& Bojanic, D. C. (1989). Multiple multinational tourism positioning using correspondence analysis. Journal of Travel Research, 28(2), 25-32.
Campubrí, R., Guía, J. \& Rodas, J. (2009). La formación de la imagen turística inducida: un modelo conceptual. PASOS, 7(2), 255-270.

Cannon Hunter, W. (2012). Projected destination image: a visual analysis of Seoul. Tourism Geographies: An International Journal of Tourism Space, Place and Environment, 14(3), 419-443.

Chen, J. S. (2001). A case study of Korean outbound travellers' destination images by using correspondence analysis. Tourism Management, 22, 345350.

Chen J. S. \& Hsu, C.H.C. (2000). Measurement of Korean tourists' perceived images of overseas destinations. Journal of Travel Research, 38(4), 411416.

Chen, J. S. \& Uysal, M. (2002): Market positioning analysis: a hybrid approach. Annals of Tourism Research, 29(4), 987-1003.

Choi, W. M., Chan, A. \& Wu, J. (1999). A qualitative and quantitative assessment of Hong Kong's image a tourist destination. Tourism Management, 20, 361-365.

Chon, K-S. (1990). The role of destination image in tourism: a review and discussion. The Tourist Review, 45(2), 2-9.

Cooper, C., Fletcher, J., Gilbert, D. \& Wanhill, S. (1993). Tourism. Principles \& Practice. London: Pitman.

Echtner, C. M. \& Ritchie, J. R. B. (1991). The meaning and measurement of destination image. The Journal of Tourism Studies, 2(2), 2-12.

Fakeye, P. C. \& Crompton, J. L. (1991). Image differences between prospective, first-time and repeat visitors to the Lower Rio Grande Valley. Journal of Travel Research, 30(2), 10-16.

Fernández Souto, A. B. (2005). O xacobeo '93 como fenómeno mediático. Revista galega de ciencias sociais, 4, 83-94.

Font, X. (1997). Managing the tourist destination's image", Journal of Vacation Marketing, 3(2), 123-131.

Galí, N. \& Donaire, J. A. (2005). The social construction of the image of Girona: a methodological approach. Tourism Management, 26, 777-785.

Gallarza, M. G. \& Gil, I. y Calderón, H. (2002). Imagen de un destino: Hacia un marco conceptual. Annals of Tourism Research en Español, 4(1), 37-62.

Gartner, W. C. (1993). Image formation process. Journal of Travel \& Tourism Marketing, 2(2-3), 191-215.

Gartner, W. C. \& Shen, J. (1992). The impact of Tiananmen Square on China's tourism image. Journal of Travel Research, 30(4), 47-52.

Gunn, C. A. (1972). Vacationscape. Designing tourist regions. Washington, DC: Taylor and Francis.

Kim, H. B. \& Richardson, S. L. (2003). Motion picture impacts on destination images. Annals of Tourism Research, 30(1), 216-237.

Kotler, P., Haider, D. H. \& Rein, Y. (1993). Marketing places: attracting investment, industry, and tourism to cities, states, and nations. New York: The Free Press.

Leisen, B. (2001). Image segmentation: the case of a tourism destination. Journal of Services Marketing, 15(1), 49-66.

Litvin, S. W. \& Maclaurin, D. J. (2001). Consumer attitude and behavior. Annals of Tourism Research, 28(3), 821-823.

Mackay, K. J. \& Fesenmaier, D.R. (1997). Pictorial element of destination in image formation. Annals of Tourism Research, 24(3), 537-565.

Middleton, V. T. C. (1994). Tourist product. En WITT, S. \& MOUTINHO, L. (Eds.). Tourism marketing and management handbook (pp. 573-576). Hempel Hempstead: Prentice-Hall.

Milman, A. \& Pizam, A. (1995). The role of awareness and familiarity with a destination: The Central Florida case. Journal of Travel Research, 33(3), 21-27.

Miossec, J. M. (1977). L'image touristique comme introduction à la géographie du tourisme. Annales de Géographie, 473, 55-70.

Morgan, N. J. \& Pritchard, A. (1998).Tourism promotion and power: creating images, creating identities. Chichester: Wiley.

Russell, J. A. \& Pratt, G. (1980). A description of the affective quality attributed to environments. Journal of Personality and Social Psychology, 38(2), 311-322.

San Martín Gutiérrez, H., Rodríguez del Bosque, I. \& Vázquez, R. (2006) Análisis de la imagen en turismo mediante técnicas estructuradas y no 
estructuradas: Implicaciones competitivas para los destinos turísticos, Revista Asturiana de Economía, 35, 69-91.

Santana Talavera, A. (2007). Imaginando la imagen en turismo: un viaje de ida y vuelta. En Seminario sobre la imagen de Andalucía en el discurso turístico (pp. 1-22). Sevilla: Centro de Estudios Andaluces. En: www.centrodeestudiosandaluces.es/datos/paginas/factoria/ideas/ponen cias_imagenandalucia_turismo.pdf.

Sanz Blas, S. (2008). Imagen global e intenciones futuras de comportamiento del turista de segunda residencia. Revista Europea de Dirección y Economía de la Empresa, 17(4), 95-114.

Sirgy, M. J. \& Su, C. (2000). Destination image, self-congruity, and travel behavior: toward an integrative model. Journal of Travel Research, 38(4), 340-352.

Tapachai, N. \& Waryszak, R. (2000). An examination of the role of beneficial image in tourist destination selection. Journal of Travel Research, 39(1), 3744.

Telisman-Kosuta, N. (1994). Tourist destination image. En WITT, S. \& Moutinho, L. (Eds): Tourism marketing and management handbook (pp. 557-561). Cambridge: Prentice Hall International.

Turgalicia (2007). Plan Estratéxico de Turismo de Galicia e Turgalicia 20072011. Santiago de Compostela: Dirección Xeral de Turismo.

Turgalicia (2010). Plan de Acción del Turismo de Galicia. Santiago de Compostela: Dirección Xeral de Turismo.

Villafañe, J. (2008a). Imagen Positiva. Gestión estratégica de la imagen de las empresas. Madrid: Pirámide.

Villafañe, J. (2008b). La gestión profesional de la imagen corporativa. Madrid: Pirámide.

Walmsley, D. J. \& Young, M. (1998). Evaluative images and tourism: the use of personal constructs to describe the structure of destinations images. Journal of Travel Research, 36(3), 65-69.

Xunta de Galicia (1994). Plan Xacobeo 93. Santiago de Compostela: Xunta de Galicia.

Xunta de Galicia (2000). Xacobeo 99. Santiago de Compostela: Xunta de Galicia.

Xunta de Galicia (2011): Memoria del Xacobeo 2010. Santiago de Compostela: S.A. de Xestión do Plan Xacobeo.

Recibido: 03.10.2015

Reenviado: 29.03.2016

Aceptado: 02.06.2016 